\title{
Characterization of geopolymer made of municipal solid waste incinera- tion ash slag
}

\author{
Yongsung Kim and Seunggu Kang ${ }^{\dagger}$ \\ Department of Advanced Materials Engineering, Kyonggi University, Suwon 443-760, Korea
}

(Received December 17, 2013)

(Revised December 23, 2013)

(Accepted December 27, 2013)

Abstract In this research, the geopolymer was fabricated using municipal solid waste incineration ash (denoted as MSWIA) slag and alkali activator, $\mathrm{NaOH}$ and its properties were analyzed. Particularly, the effects of $\mathrm{NaOH}$ molarity, particle size of MSWIA, and liquid/solids ratio on the compressive strength of geopolymers were investigated. The compressive strength of geopolymers fabricated increased with finer grain size of MSWIA, and optimum value of the liquid/solids ratio was identified as 0.13 . As the molarity of the $\mathrm{NaOH}$ increased, the compressive strength of geopolymers was increased. Even more the $20 \mathrm{M}$ of $\mathrm{NaOH}$, but the strength was not increased. The calcium aluminum silicate and calcium aluminum silicate hydrate zeolites were generated in the geopolymer fabricated with more than $20 \mathrm{M}$ of $\mathrm{NaOH}$, with some unreacted silica and unknown crystals remained. The highest compressive strength, $163 \mathrm{MPa}$, of geopolymer was appeared at conditions of curing temperature $70^{\circ} \mathrm{C}$, and $20 \mathrm{M}$ of $\mathrm{NaOH}$, indicating that the high concentration of $\mathrm{NaOH}$ accelerates the geopolymer reaction and dense microstructure. The high-strength geopolymer fabricated in the present study is expected to contribute significantly to develop the field of cement alternative substances and to improve the recycling rate of MSWIA slag.

Key words Geopolymer, Municipal solid waste incineration ash, Slag, NaOH, Zeolite

\section{도시쓰레기 소각재 슬래그로 제조된 지오폴리머의 특성}

\author{
김용성, 강승구 \\ 경기대학교 신소재공학과, 수원, 443-760 \\ (2013년 12월 17일 접수) \\ (2013년 12월 23일 심사완료) \\ (2013년 12월 27일 게재확정)
}

요 약 본 연구에서는 도시 쓰레기 소각재 슬래그에 알칼리 활성화제로서 $\mathrm{NaOH}$ 를 첨가하여 지오폴리머를 합성하고 그 물성을 평가하였다. 특히 $\mathrm{NaOH}$ 의 몰농도, 원료의 입도 그리고 액체/고체 비율이 제조된 지오폴리머의 압축강도에 미치 는 영향을 조사하였다. 원료의 입도가 미세할수록 합성된 지오폴리머의 강도는 증가하였으며, 액체/고체 비율의 최적 값은 0.13 으로 나타났다. 합성된 지오폴리머의 압축강도는 첨가된 $\mathrm{NaOH}$ 의 몰농도가 증가함에 따라 함께 증가하는 경향을 나타 내었으나, $20 \mathrm{M}$ 이상의 농도에서는 일정 값에 수렴하였다. $20 \mathrm{M}$ 이상의 $\mathrm{NaOH}$ 농도로 제조된 지오폴리머에는 sodium aluminum silicate 및 sodium aluminum silicate hydrate 형태의 2종류 zeolite 결정상이 생성되었다. $20 \mathrm{M} \mathrm{NaOH}$ 및 $70^{\circ} \mathrm{C}$ 양 생조건으로 제조된 시편에서 가장 높은 압축강도, $163 \mathrm{MPa}$ 이 발현되었으며, 이것은 고농도의 $\mathrm{NaOH}$ 가 지오폴리머 반응 및 치밀한 미세구조 형성을 촉진시켰기 때문인 것으로 사료된다. 본 연구에서 제조된 고강도의 지오폴리머는 향후, 도시쓰레 기 소각재 슬래그의 재활용율 제고는 물론 시멘트 대체 분야 발전에 일조할 것으로 기대된다.

1. 서 론

건설 산업에서 가장 많이 사용되는 재료중 하나인 시

\footnotetext{
Corresponding author

Tel: +82-31-249-9767

Fax: +82-31-249-9774

E-mail: sgkang@kgu.ac.kr
}

멘트는 그 생산과정에서 다량의 $\mathrm{CO}_{2}$ 가 배출되며, 그 양 이 연간 총 배출량의 $5 \sim 7 \%$ 를 차지하는 것으로 알려져 있다 $[1,2]$. 한편 시멘트의 대체 재료로 주목받고 있는 지오폴리머는 제조과정에서 $\mathrm{CO}_{2}$ 배출이 거의 없기 때문 에 친환경 재료로 최근 큰 관심을 끌고 있다 $[3,4]$. 지오 폴리머는 알루미노 규산염 물질에 알칼리 활성제를 첨가 하여 소성과정을 거치지 않고 경화시킨 우수한 화학적, 
기계적 특성을 갖는 재료이다[5-9]. 지오폴리머의 원료로 사용될 수 있는 물질로는 산업부산물/폐기물로서 비산재 (fly ash) 및 슬래그(slag)가 대표적이고, 천연원료로는 점토 및 하소 카올린(kaolin)등이 있다[10, 11].

최근 대량생산 및 소비 경향이 두드러짐에 따라 다량의 생활 폐기물이 발생되고 있으나, 폐기물 매립장의 부지확 보가 점차 어려워지면서 소각처리가 매우 유용한 폐기물 처리방법 중 하나로 정착되고 있다. 그러나 소각장에서 배 출되는 소각재의 양도 증가 추세인 실정으로 2002년 국내 전체 소각재 발생량은 377,495 톤이었으나, 2012년에는 638,328 톤으로 10 년 사이에 약 2 배 가까이 증가하였다 [12].

이러한 일반 도시 쓰레기 소각재는 많은 중금속들을 함유하기 때문에 원료로서 재활용하기에 환경적인 어려 움을 갖고 있다[13-16]. 소각재를 고온으로 용융하여 유 리질로 만든 것이 도시 쓰레기 소각재 슬래그이다. 슬래 그는 용융과정에서 중금속들이 $\mathrm{Si}-\mathrm{O}$ 비정질 망목구조 내에 고정되므로 소각재에 비해 물리 화학적으로 매우 안정하다 $[13,17,18]$.

본 연구의 목적은 도시 쓰레기 소각재 슬래그를 사용 하여 지오폴리머를 제작하고, 이것이 시멘트 대체재로 가능한 지 여부를 분석하는 것이다. 이를 위하여 알칼리 활성화제로서 $\mathrm{NaOH}$ 를 이용하고 원료입도, 액체/고체 비 율, 몰농도에 따른 지오폴리머의 압축 강도를 측정하였 다. 특히 결정상 분석과 미세구조 관찰결과를 지오폴리 머의 기계적 특성과 연계하여 고찰하였다.

\section{2. 실험방법}

지오폴리머를 제조하기 위한 원료로서 경기도 소재 "A" 도시 쓰레기 소각장에서 배출된 소각재(MSWIA: municipal solid waste incineration ash) 슬래그를 사용 하였다. MSWIA 슬래그의 화학조성을 X-ray fluorescence spectrometer(XRF, SPECTRO 2000)를 이용하여 측정한 결과, 주 성분은 $\mathrm{SiO}_{2}$ 와 $\mathrm{Al}_{2} \mathrm{O}_{3}$ 인 것을 확인할 수 있었다 (Table 1). 도시 쓰레기 소각장에서 가져온 MSWIA 슬래 그의 SEM 사진(Fig. 1)을 보면 수십 수백 $\mu \mathrm{m}$ 의 다양한 크기를 가진 불규칙한 모양의 입자들로 구성되어 있음을 알 수 있다. MSWIA 슬래그는 사용 전에 체거름을 통하 여 $45 \mu \mathrm{m}$ 이하, 75 100 $\mu \mathrm{m}$, 그리고 $100 ~ 150 \mu \mathrm{m}$ 으로 입

Table 1

Chemical compostition of MSWIA slag determined by XRF (wt\%)

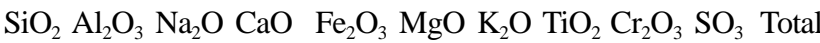

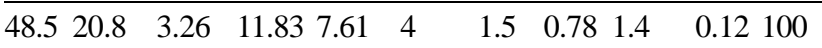

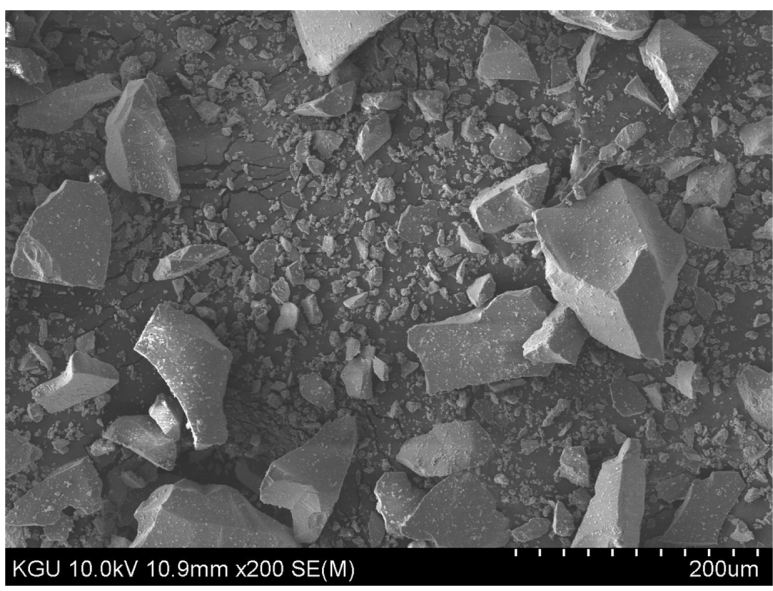

Fig. 1. SEM image of as-received MSWIA slag.

도가 다른 3종류의 원료로 준비하였다.

알칼리 활성화제는 상온에서 증류수와 $\mathrm{NaOH}$ 를 혼합, 교반하여 제조하였으며, 그 몰농도는 10 25 M 범위내에 서 조정하였다. 원료 혼합시 액체 대 고체 무게비, 즉 L/S ratio(liquid/solid ratio)는 0.1 0.15 범위로 변화시켰 다. 원료와 활성화제를 혼합시킨 반죽물을 스테인리스 몰드에 넣고 프레스 기기로 $316 \mathrm{~kg} / \mathrm{cm}^{2}$ 압력을 가하여 지름 $10 \mathrm{~mm}$, 높이 $10 \mathrm{~mm}$ 의 실린더 모양의 시편을 성 형하였다. 프레스 법으로 시편을 제조하면 공극 및 기공 이 줄어들어 기계적 강도가 향상된다. 제조된 시편은 급 격한 수분 증발을 방지하기 위하여 폴리에틸렌 지퍼백으 로 밀봉한 상태에서 $70^{\circ} \mathrm{C}$ 에서 24 시간 동안 양생시킨 후, 상온에서 1 3일 간 재령을 실시하였다.

제조된 지오폴리머의 결정상 분석은 X-Ray diffractometer(XRD, Rigaku MiniFlex2)를 사용하여 $40 \mathrm{kV}$ 와 $40 \mathrm{~mA} \mathrm{Cu} \mathrm{K \alpha}$ radiation 조건으로 수행하였다. 지오폴리 머의 미세구조는 scanning electron microscopy(SEM, S-4800 HITACHI, Japan)을 이용하였으며, 백금 코팅 후 $5 \mathrm{kV}$ 가속전압 조건으로 관찰하였다. 압축강도는 universal testing machine(UTM-900NH Series DAEKYUNG, Korea) 을 이용하여 $5 \mathrm{~cm} / \mathrm{min}$ 의 헤드 속도로 $3 \sim 5$ 개 시편을 측 정하여 평균값을 산출하였다.

\section{3. 결과 및 고찰}

첨가된 활성화제 몰농도에 따른 지오폴리머의 상분석 결과를 Fig. 2에 나타내었다. As-received 원료는 $15^{\circ}$ $38^{\circ}$ 범위에서 비정질을 의미하는 커다란 언덕 모양 피크 를 나타냈다. 또한 결정상으로는 quartz 및 cristobalite 구조의 실리카, calcium silicate hydrate 그리고 확인되지 않는 미지 결정 등이 함유되어 있었다. 지오폴리머 반응 에서 원료내 비정질상은 결정질 상에 비해 알루미나와 


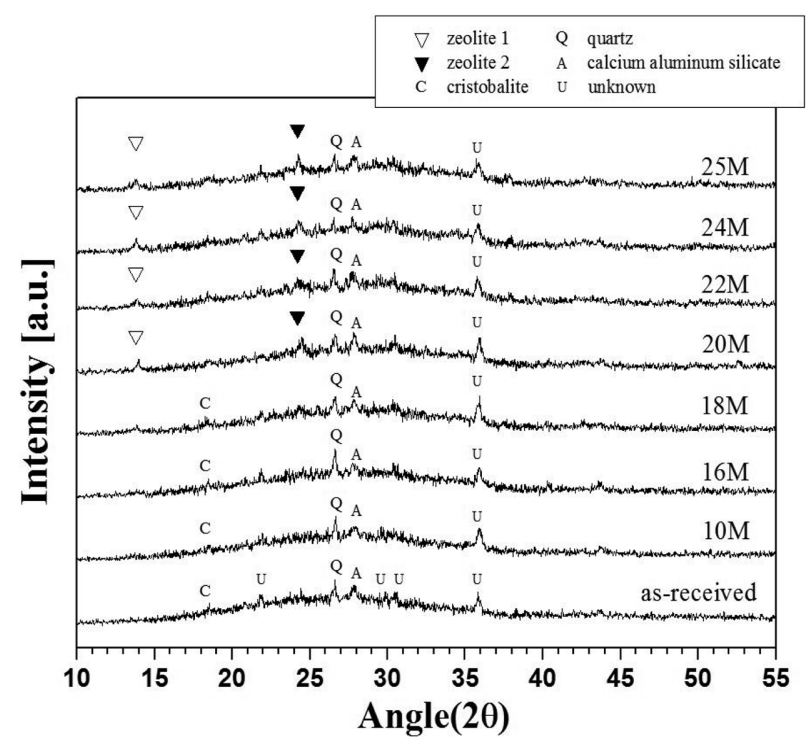

Fig. 2. Phase analysis of geopolymers mad of MSWIA slag with different concentration of $\mathrm{NaOH}$. The zeolite 1 and 2 mean sodium aluminum silicate hydrate (JCPDS\#: 86-2218) and sodium aluminum silicate (JCPDS\#: 47-0356), respectively.

실리카 이온을 쉽게 용출시켜 dissolution-reorientationsolidification 과정을 촉진시킨다고 알려져 있다[19]. 한
편 MSWIA 슬래그로 제조된 지오폴리머에는 sodium aluminum silicate hydrate(zeolite 1) 및 sodium aluminum silicate(zeolite 2) 결정상이 생성되었고, 미반응된 quartz 및 calcium aluminum silicate 상들이 잔존하였다. 특히 zeolite 1 및 2 결정상은 첨가된 $\mathrm{NaOH}$ 의 농도가 $20 \mathrm{M}$ 이상으로 제조된 지오폴리머에서만 생성되었다. Duxson 등은 지오폴리머가 XRD 패턴 상 비정질일지라도 어느 수준의 ordering이 존재하며, 온도, 시간 또는 알칼리 활 성화제 농도 등 공정조건에 따라 비정질의 지오폴리머가 zeolite 결정질로 전이된다고 하였다[20]. 따라서 $20 \mathrm{M}$ 농도 이상의 $\mathrm{NaOH}$ 로 제조된 지오폴리머에 zeolite 결정 피크가 나타난 것은 활발한 지오폴리머 반응이 일어났음 을 보여준 것으로 생각된다.

Fig. 3에 $\mathrm{NaOH}$ 몰농도 변화에 따른 MSWIA 슬래그 로 제조된 지오폴리머의 파괴단면 미세구조를 나타내었 다. 전체적인 시편의 기공과 공극을 관찰하기 위하여 먼 저 3,000배의 저배율로 관찰하였다. 저배율 사진을 보면 $\mathrm{NaOH}$ 몰농도가 증가함에 따라 미세구조가 치밀해지는 것을 확인할 수가 있다. 나노미터 크기의 미세구조를 분 석하기 위하여 관찰된 50,000 배의 고배율 사진을 저배 율 사진 내, 우측 상단에 나타내었다. $10 \sim 16 \mathrm{M}$ 시편의

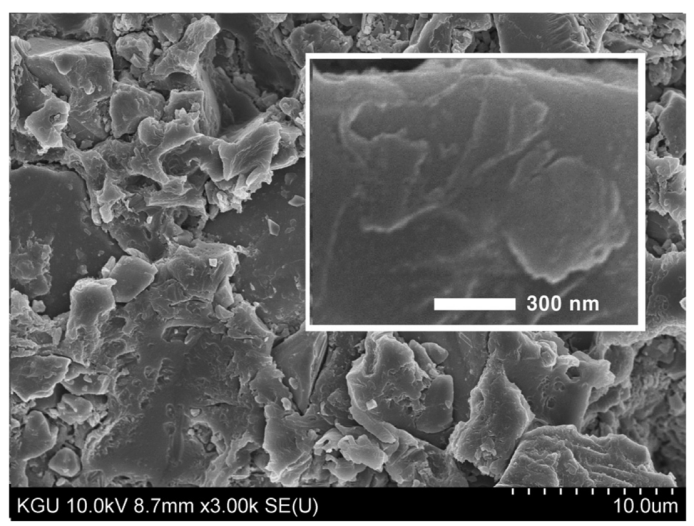

$10 \mathrm{M}$

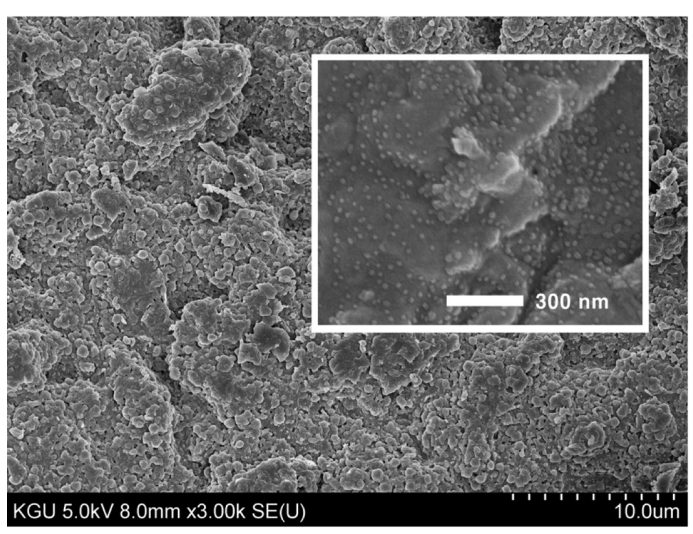

$20 \mathrm{M}$

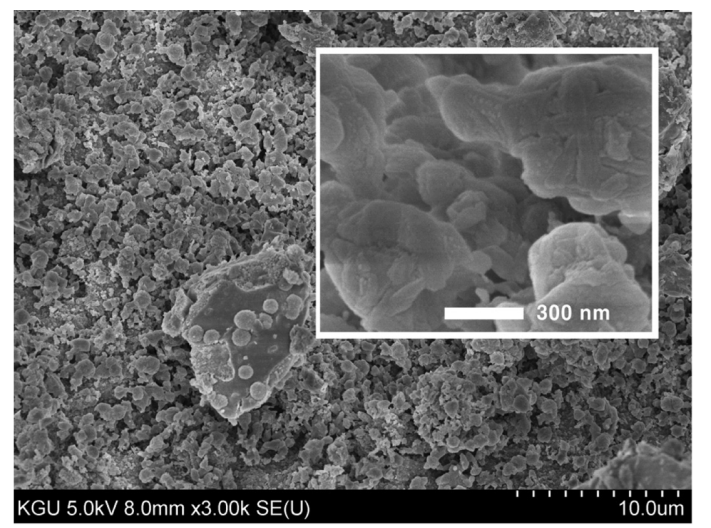

$16 \mathrm{M}$

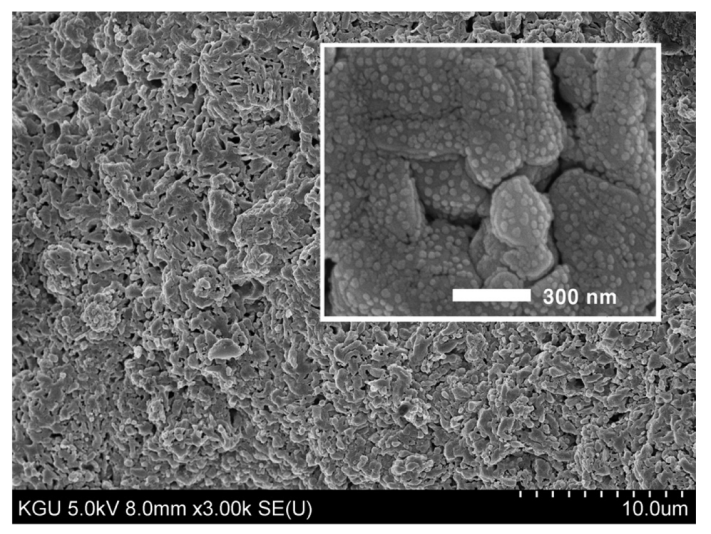

$24 \mathrm{M}$

Fig. 3. Microstructure of fractured surface for geopolymers made of MSWIA slag. The highly magnified $(\times 50,000)$ pictures are put in upper right at each corresponding picture of lower magnified $(\times 3,000)$. 
고배율 사진을 보면, 지오폴리머 반응으로 수백 나노미 터 크기 입자들이 결합되어 matrix를 이루고 있음을 알 수 있다. 그러나 수 나노미터 크기의 미세 결정입자는 관측되지 않았다. 한편, $20 \mathrm{M}$ 시편의 고배율 사진을 보 면 지오폴리머 matrix에 수 나노미터 크기의 매우 미세 한 결정입자들이 형성되었고, $24 \mathrm{M}$ 시편의 고배율 사진 에서는 그 미세결정이 수십 나노미터 크기로 성장된 것 을 볼 수 있다. 이는 알칼리 활성화제 농도증가에 따라 $\mathrm{Al}$ 과 $\mathrm{Si}$ 이온이 더 쉽게 용출되어 지오폴리머 반응이 효 과적으로 진행되었기 때문으로 생각된다.

MSWIA 슬래그로부터 지오폴리머를 제조함에 있어 원 료 입도 및 $\mathrm{L} / \mathrm{S}$ ratio가 지오폴리머의 압축강도에 미치는 영향을 측정하여 각각 Fig. 4 및 5 에 나타내었다. 3 가지 종류의 입도 즉, $45 \mu \mathrm{m}$ 이하, 75 100 $\mu \mathrm{m}$ 그리고 100 $150 \mu \mathrm{m}$ 로 제조된 지오폴리머의 압축강도 측정 결과, $45 \mu \mathrm{m}$ 이하의 입도를 사용하였을 때 가장 높은 압축강도

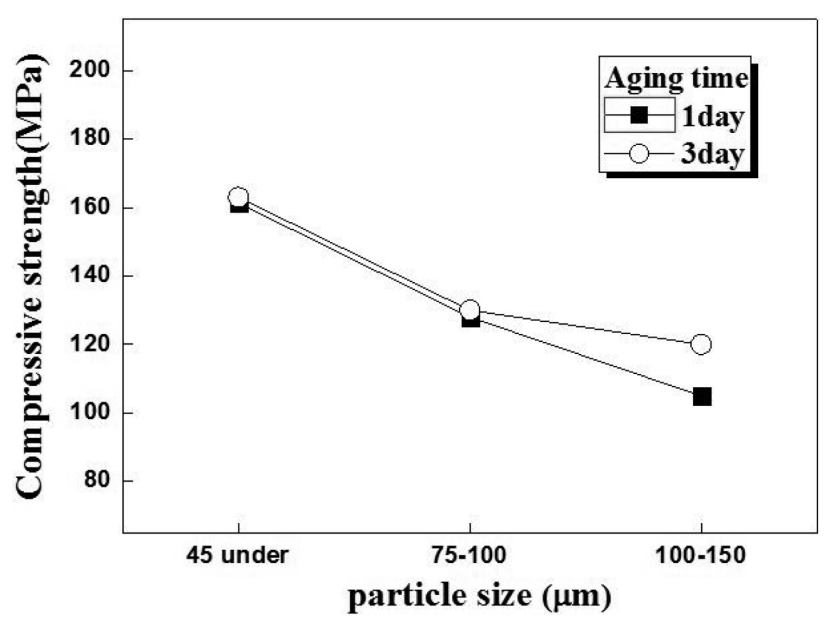

Fig. 4. The compressive strength of geopolymers as a function of particle size of MSWIA slag. The liquid/solid ratio was 0.13 .

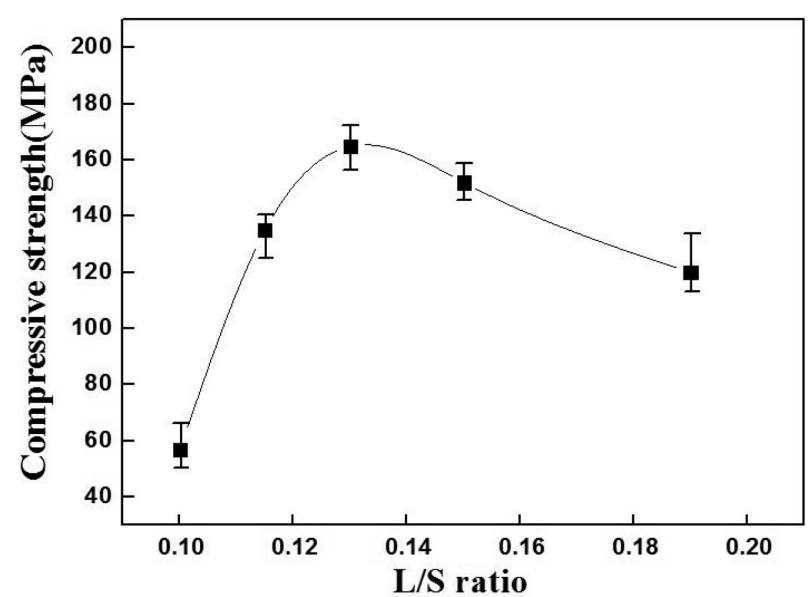

Fig. 5. The compressive strength for geopolymers mad of MSWIA slag as a function of liquid/solid ratio. The aging time was for 1 day.
를 나타내었다. 이는 입도가 미세할수록 단위 무게 당 비 표면적이 증가하여 알칼리 활성화제와 접촉시 $\mathrm{Si}$ 및 $\mathrm{Al}$ 이온 용출이 용이하였고 그 결과 지오폴리머 반응이 촉 진되었기 때문으로 생각된다. 동시에 미세입자의 높은 충 진효율도 강도 증진에 도움이 되었을 것으로 생각된다.

한편 $70^{\circ} \mathrm{C}$ 에서 $24 \mathrm{hr}$ 양생 후 1 및 3 일 간 재령시킨 시편의 강도를 비교해 보면, 입도가 미세한 원료를 사용 한 경우에는 재령시간에 따른 강도변화가 거의 없었으나, 굵은 입도를 사용한 경우, 재령일이 강도 증진에 기여하 였다. 이에 대한 정확한 분석은 추가적인 연구가 필요하 다고 생각된다. 따라서 본 연구에서는 MSWIA 슬래그 원료를 $45 \mu \mathrm{m}$ 이하인 것 만을 선별하여 사용하였고, 재 령은 1 일로 정하였다. 한편 성형시 $\mathrm{L} / \mathrm{S}$ ratio 값은 가장 높은 지오폴리머 강도 값이 발현된 $\mathrm{L} / \mathrm{S}$ ratio $=0.13$ 으로 정하였다(Fig. 5).

알칼리 활성화제 몰농도에 따른 1 일차 압축강도 결과 를 Fig. 6에 나타내었다. 압축강도는 몰농도에 따라 증 가하는 경향을 나타냈으며, $20 \mathrm{M}$ 시편에서 약 $163 \mathrm{MPa}$ 로 최대 강도를 나타내었다. $20 \mathrm{M}$ 이상의 몰농도에서는 더 이상 압축강도가 증가되지 않았다. $70^{\circ} \mathrm{C} / 24 \mathrm{~h}$ 의 조건 으로 양생된 지오폴리머의 압축강도 값은 일반적인 시멘 트 모르타르의 45 60 MPa[21]와 비교하였을 때 매우 높은 값으로 향후 시멘트 대체 재료로 충분히 활용이 될 것으로 생각된다.

MSWIA 슬래그로 제조된 지오폴리머의 압축강도 결 과는 그 미세구조(Fig. 3) 및 XRD 결과(Fig. 2)를 통해 설명할 수 있다. 지오폴리머 모상 내 공극 및 기공은 알 칼리 활성화제의 몰농도가 증가함에 따라 감소되어 치밀 한 구조를 나타내었다(Fig. 3). Fig. 3의 50,000배 확대 미세구조에서 수-수십 나노미터 크기의 결정입자가 생성

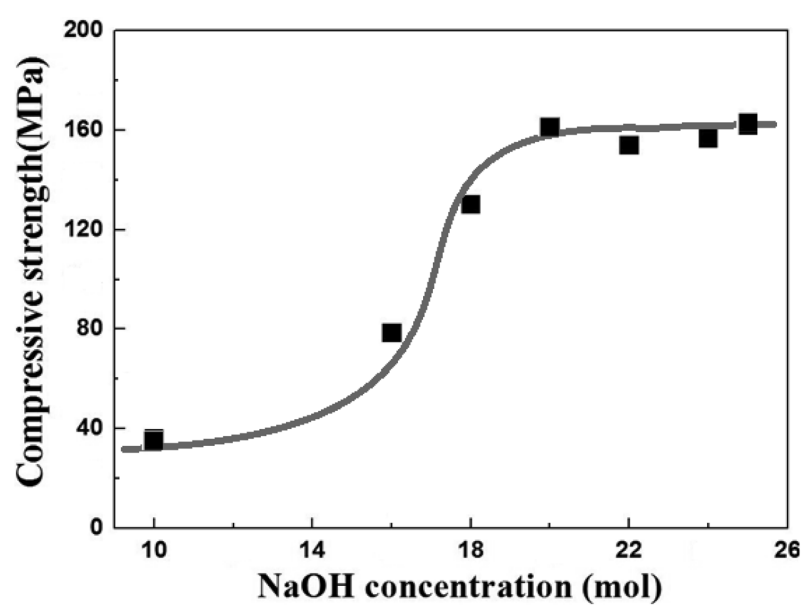

Fig. 6. The compressive strength for geopolymers made of MSWIA slag as a function of alkali activator, $\mathrm{NaOH}$ concentration. The particle size of starting material and aging time for fabricating geopolymer are $45 \mu \mathrm{m}$ and 1 day, respectively. 
된 것이 확인되었다. 이는 XRD 결과(Fig. 2)에서 zeolite 결정피크로 확인되었으며, 따라서 $20 \mathrm{M}$ 이상 몰농도 시 편에서 지오폴리머 반응이 매우 활발히 일어났음을 알 수 있다. Kim 등에 의하면 지오폴리머에서 나타나는 결 정상들은 순수한 지오폴리머와 비교하였을 때보다 증가 된 압축강도를 나타내며 이를 'composite effect'라 하였 다[22]. 따라서 $20 \mathrm{M}$ 이상 농도에서 최대 압축강도를 나 타낸 것은 지오폴리머반응에 의한 치밀화 및 결정상 형 성에 따른 강화의 두 가지 효과가 복합적으로 작용한 것 으로 생각된다.

\section{4. 결 론}

본 연구에서는 도시쓰레기 소각재(MSWIA) 슬래그를 이용하여 지오폴리머를 제조, 분석하여 다음과 같은 결 론을 얻었다.

1) MSWIA 슬래그 원료의 입도가 미세할수록 지오폴 리머의 압축강도는 높게 나타났으며, 이는 입도가 미세 할수록 충진 효율이 증가됨은 물론 비표면적이 증가하여 지오폴리머 반응이 촉진되었기 때문으로 판단된다. 한편 liquid/solid ratio $=0.13$ 으로 제조된 지오폴리머가 가장 높은 강도 값을 나타냈다.

2) 알칼리 활성화제인 $\mathrm{NaOH}$ 몰농도 증가에 따라 제 조된 지오폴리머의 압축강도 역시 증가하는 경향을 나타 냈으며, $20 \mathrm{M}$ 시편에서 약 $163 \mathrm{MPa}$ 로 최대 강도를 나 타내었다. 이는 $\mathrm{NaOH}$ 몰농도가 증가함에 따라 지오폴 리머 내 공극 및 기공이 감소되어 구조가 치밀해졌고 동 시에 수-수십 나노미터 크기의 zeolite 결정립 입자들이 생성되어 모상을 강화시켰기 때문으로 판단된다.

3) 본 연구에서는 제조된 MSWIA 슬래그 지오폴리머 의 압축강도는 일반적인 시멘트 모르타르와 비교하여 매 우 높은 값으로, 향후 시멘트 대체 재료로 활용이 가능 할 것으로 생각된다. 아울러 본 연구 결과를 활용하면 MSWIA 슬래그의 재활용율을 크게 높일 수 있을 것으 로 기대된다.

\section{감사의 글}

"본 연구는 2014년도 경기대학교 대학원 연구원장학생 장학금 지원에 의하여 수행되었음."

\section{참 고 문 헌}

[ 1 ] P. Friedlingstein, R. Houghton, G. Marland, J. Hackler,
T. Boden, T. Conway, J. Canadell, M. Raupach, P. Ciais and C. Le Quere, "Update on $\mathrm{CO}_{2}$ emissions", Nat. Geosci. 12 (2010) 811.

[2] J.M. Allwood, J.M. Cullen and R.L. Milford, "Options for achieving a $50 \%$ cut in industrial carbon emissions by 2050", Part. Sci. Technol. 44 (2010) 1888.

[3] K. Komnitas and D. Zaharaki, "Geopolymerisation; A review and prospects for the minerals industry", Miner. Eng. 20 (2007) 1261.

[4] Y.T. Kim, H.J. Kim and C.S. Jang, "Characteristics of geopolymer based on recycling resources", J. Korean Cryst. Growth Cryst. Technol. 22 (2012) 152.

[5] J. Davidovits, "The polysialate terminology: A very useful and simple model for the promotion and understanding of green-chemistry, in geopolymer, green chemistry and sustainable development solutions", Proceedings of the world congress geopolymer, Geopolymer Institute, Saint-Quentin, France. Ed. (2005) 9.

[6] R.A. Fletcher, K.J.D. Mackenzie, C.L. Nicholson and S. Shimada, "The composition range of aluminosilicate geopolymers", J. Eur. Ceram. Soc. 25 (2005) 1471.

[ 7 ] J.G.S. van Jaarsveld, J.S.J. van Deventer and L. Lorenzen, "The potential use of geopolymeric materials to immobilise toxic metals", Miner. Eng. 10 (1997) 659.

[8] J. Davidovits, "Geopolymers: inorganic polymeric new materials", Therm. Anal. 37 (1991) 1633.

[9] P. Duxson, J.L. Provis, G. Lukey, S.J. Jannie and V. Deventer, "The role of inorganic polymer technology in the development of green concrete", Cem. Concr. Res. 37 (2007) 1590.

[10] J.K. Lee, Y.S. Choo and S.J. Jung, "Situation and prospect of Geopolymer", Ceramist. 9 (2006) 44.

[11] Y.T. Kim, H.J. Kim and C.S. Jang, "Property enhancement of geopolymer by means of separation/classification of spent-resources", J. Korean Cryst. Growth Cryst. Technol. 22 (2012) 299.

[12] Annual Report: Status of operation of the resource recovery facility of municipal waste, Ministry of Environment, Korea (2012)

[13] K. Sreenivasarao, G.W. Warren, M.D. Mckinley and G. Gao, "Hydrometallurgical treatment of municipal solid waste fly-ash for simultaneous detoxification and metal recovery", J. Environ. Sci. Health A32 (1997) 1225.

[14] K.L. Lin and C.T. Chang, , "Leaching characteristics of slag from the melting treatment of municipal solid waste incinerator ash", J. Hazard. Mater. B135 (2006) 296.

[15] J.E Aubert, B. Husson and N. Sarramone, "Utilization of municipal solid waste incineration (MSWI) fly-ash in blended cement: Part 2. Mechanical strength of mortars and environmental impact", J. Hazard. Mater. 146 (2007) 12.

[16] Q. Wang, S. Tian, Q. Wang, Q. Huang and J. Yang, "Melting characteristics during the vitrification of MSWI fly ash with a pilot-scale diesel oil furnace", J. Hazard. Mater. 160 (2008) 376.

[17] K.L. Lin, K.S. Wang, B.Y. Tzeng and C.Y. Lin, "The reuse of municipal solid waste incinerator fly ash slag as a cement substitute", Res. Conserv. and Recyc. 39 (2003) 315.

[18] K.L. Lin, K.S. Wang and C.H. Lin "The hydration prop- 
erties of pastes containing municipal solid waste incinerator fly ash slag", J. Hazard. Mater. B109 (2004) 173.

[19] J. He, Y. Jie, J. Zhang, Y. Yu and G. Zhang, "Synthesis and characterization of red mud and rice husk ash-based geopolymer composites", Cem. Concr. Comp. 37 (2013) 108.

[20] P. Duxson, "Geopolymer technology: the ccurrent state of the art”, J. Mater. Sci. 42 (2007) 2917.
[21] J. Ambroise, M. Murat and J. Pera, "Hydration reaction and hardening of calcined clays and related minerals V. Extension of the research and general conclusions", Cem. Concr. Res. 15 (1985) 261.

[22] J.T. Kim, D.S. Seo, G.J. Kim and J.K. Lee, "Influence of alkaline-activator content on the compressive strength of aluminosilicate-based geopolymer", J. Kor. Ceram. Soc. 47 (2010) 216 